\title{
$\mathrm{YCbCr}$ 컬러 모델에서의 조건 검사와 적응적 차영상을 이용한 화염 및 연기 검출 알고리즘
}

\author{
이 두 희 ${ }^{*}, \quad$ 유 재 욱 ${ }^{*}, \quad$ 이 강 희 ${ }^{*}, \quad$ 김 윤 ${ }^{* *}$
}

\section{A Real Time Flame and Smoke Detection Algorithm Based on Conditional Test in YCbOr Color Model and Adaptive Differential Image}

\author{
Doo-Hee Lee ", Jae-Wook Yoo , Kang-Hee Lee ", Yoon Kim ${ }^{* *}$ \\ 요 약
}

\begin{abstract}
본 논문에서는 감시 카메라를 통해 입력된 영상 정보로 연기와 화염을 실시간 검출하는 알고리즘을 제안한다. 산불은 막대한 인명, 재산피해를 불러오기 때문에 조기 감지에 따른 초기 진화가 매우 중요하다. 제안하는 산불 감 시 알고리즘은 화염 감지와 연기 감지로 나뉘는데, 화염 감지는 단일 프레임에서 $Y C b C r$ 컬러 모델에서의 조건 검 사를 통하여 화염을 검출한다. 연기 감지를 위해서는 먼저 현재 영상과 인접한 프레임들의 평균 영상사이의 차를 가 중치로 이용하여 배경 범위를 설정하고, 이 범위를 벗어나면서 회색조를 갖는 픽셀만을 연기영역으로 검출한다. 제 안하는 화염 감지 알고리즘은 기존의 알고리즘보다 일조량에 따른 조도의 변화에 강건하고, 연기 검출 알고리즘은 단위 시간동안의 변화량을 고려하여 회색조의 픽셀만을 연기로 감지하기 때문에 효과적인 조기 산불 탐지가 가능하 다. 실험 결과는 제안하는 산불 감시 알고리즘이 기존의 알고리즘보다 우수한 성능을 나타냄을 보여준다.
\end{abstract}

\begin{abstract}
In this paper, we propose a new real-time algorithm detecting the flame and smoke in digital CCTV images. Because the forest fire causes the enormous human life and damage of property, the early management according to the early sensing is very important. The proposed algorithm for monitoring forest fire is classified into the flame sensing and detection of smoke. The flame sensing algorithm detects a flame through the conditional test at $Y C O C$ color model from the single frame. For the detection of smoke, firstly the background range is set by using differences between current picture and the average picture among the adjacent frames in the weighted value, and the pixels which get out of this range and have a gray-scale are detected in the smoke area. Because the proposed flame sensing algorithm is stronger than the existing algorithms in the change of the
\end{abstract}

- 제1저자 : 이두희 교선저자 : 김 윤

- 투고일 : 2010. 04. 05, 심사일 : 2010. 04. 07, 게재확정일 : 2010. 04. 13.

* 강원대학교 컴퓨터정보통신공학 석사과정 ** 강원대학교 컴퓨터정보통신공학 부교수

※ 이 논문은 2010 년 한국컴퓨터정보학회 제 41 차 동계학술대회에 발표한 "실시간 산불 감지를 위한 화염 및 연기 검출 기법”[1]을 확장한 것임. 
illuminance according to the quantity of sunshine, and the smoke detection algorithm senses the pixel of a gray-scale with the smoke considering the amount of change for unit time, the effective early forest fire detection is possible. The experimental results indicate that the proposed algorithm provides better performance than existing algorithms.

- Keyword : 산불(Forest Fire), 화염 검출(Fire Detection), 연기 검출(Smoke Detection)

\section{I. 서 론}

최근 환경에 대한 중요성이 높아지면서 조기 산불 감지에 대 한 관심도 날로 증가하고 있다. 산불은 초기 진화에 실패하면 대형화재로 확산되고, 그 결과로 인해 많은 인명, 재산 피해를 가져오기 때문에 조기 탐지에 따른 초기 진화가 매우 중요하다.

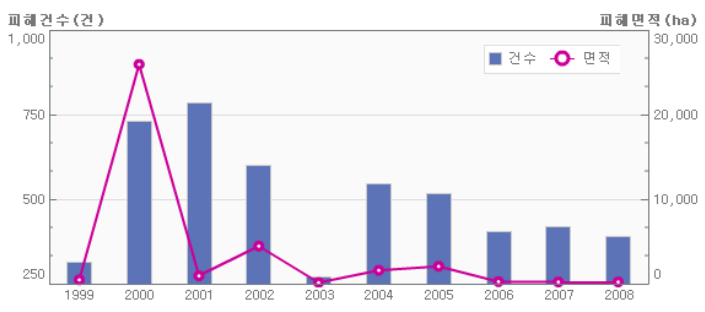

그림 1. 산불 피해 현황

Fig 1. Current extent of damage by forest fire.

하지만 현재 산불감시는 대부분 사람이 직접 육안으로 관 찰하고 있기 때문에, 야간이나 관리자의 부재 시에는 산불의 확산 위험이 매우 크다. 따라서 산불로 인한 피해를 최소화하 기 위해서는 산불을 조기 검출할 수 있는 시스템이 요구된다. 또한, 기존에 설치되어있는 시스템을 그대로 이용하기위해서 는 $\mathrm{CCTV}$ 의 영상정보만을 이용하여 화염이나 연기를 검출할 수 있는 알고리즘의 개발이 요구된다.

기존의 화염 검출 기법은 $R G B$ 컬러 모델을 이용하는 방 법 $\{2,3,4,5]$ 과 $Y C b C r$ 컬러 모델을 이용하는 방법 $[6,7]$ 이 있다. 이와 같은 방법은 화재 발생 시 검출 성능은 뛰어나지 만 오검출 비율도 높기 때문에 추가 정보를 이용하여 산불 발 생 여부를 판단해야 한다. 또한, 이전 프레임과의 차이를 이 용하거나 $[8,9]$ 화염의 패턴을 이용하는 화염 검출 알고리즘 〔10]도 연구되었지만 산불 감시와 같은 원거리 촬영에는 적 합하지 않다. 기존의 연기 검출 알고리즘은 Wavelet 변환을 이용하는 방법[11,12,13]이 대표적이지만 산불감시 같은 원 거리 영상에서는 주파수 특성이 효과적으로 나타나지 않아서
적합하지 않다. 차영상을 이용하는 방법[14]도 있지만 차영 상에서 연기가 발생한 구간을 판단하는 범위가 제한적이다. 그 외에도 터널에서 발생하는 화재를 탐지하는 방법 $[15,16]$ 과 $\mathrm{Pan} / \mathrm{Tilt}$ 를 장착한 비행체를 이용하여 상공에서 산불을 감시하는 방법[17]도 연구되었다. 하지만 화재의 발생 장소 가 다르고, 기존에 설치된 $\mathrm{CCTV}$ 를 이용하지 않는다는 점에 서 적용할 수 있는 환경에 제한이 있다.

본 논문에서는 입력되는 영상에서 화염 검출과 연기 검출 정보를 이용하여 정확하게 산불 발생 여부를 판단할 수 있는 알고리즘을 제안한다. 화염 검출은 단일 프레임에서 $Y C O C$. 성분의 평균을 구하고 각 픽셀단위로 평균값과의 적절한 조건 을 검사하여 최종적으로 화염 발생 여부를 판별한다. 연기 검 출은 인접한 프레임들의 영상 평균을 구하고 현재 영상과의 차영상을 구한다. 이 차영상을 배경 후보 범위를 결정하는 가 중치로 이용한다. 현재 입력 영상 픽셀 중에서 위에서 설정 된 범위에서 벗어나고 회색조(Gray scale)를 갖는 픽셀을 연 기 영역으로 판단한다.

본 논문의 구성은 다음과 같다. 파장과 피장에서는 제안하 는 화염 및 연기 검출 알고리즘을 기술하고, IV장에서는 실험 결과를 통해 그 성능을 확인하며, 최종적으로 $\mathrm{V}$ 장에서 결론 을 맺는다.

\section{II. 화염 검출 알고리즘}

\section{1 영상 모델 변환 및 평균 성분 값 계산}

카메라에서 촬영된 영상은 $R G B$ 컬러로 시스템에 전달된 다. 본 시스템에서는 휘도 값과 색차성분을 이용하여 화염을 판단하기 때문에 입력된 $R G B$ 를 $Y G C$ 로 변환한다. $R G B$ 컬러를 $Y C O C$ 컬러 모델로 변환하는 공식은 (1)과 같이 정 의된다[18].

$$
\left[\begin{array}{c}
Y \\
C b \\
C r
\end{array}\right]=\left[\begin{array}{rrr}
0.2568 & 0.5041 & 0.0979 \\
-0.1482 & -0.0910 & 0.4392 \\
0.4392 & -0.3678 & -0.0714
\end{array}\right]\left[\begin{array}{l}
R \\
G \\
B
\end{array}\right]+\left[\begin{array}{c}
16 \\
128 \\
128
\end{array}\right]
$$


여기서 $Y$ 는 휘도를 나타내며 $C b$ 와 $C r$ 은 색차 값을 나타낸 다. 또한 화염 검출을 위해서는 단일 프레임에서 $\mathrm{YCbCr}$ 각 각의 평균 성분 값을 구하며 그 공식은 아래 (2)와 같다.

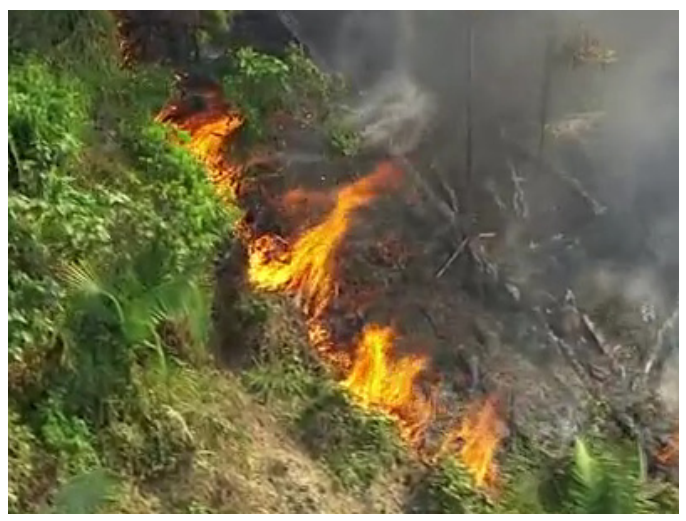

(a) 영상 입력

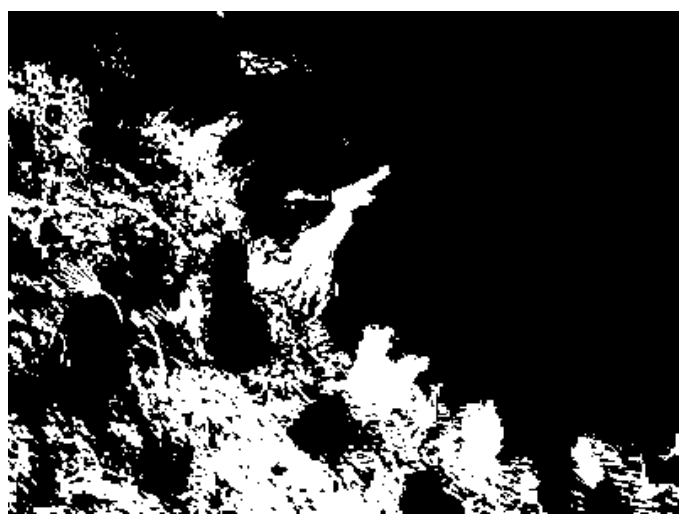

(c) 입력 영상에 대한 $F^{\prime}(x, y)$
를 시행한다. 조건 검사는 Celik[3]의 알고리즘을 사용한다. 이 알고리즘은 $R G B$ 컬러 공간에서 다음과 같은 두가지 조건 을 이용한다[5].

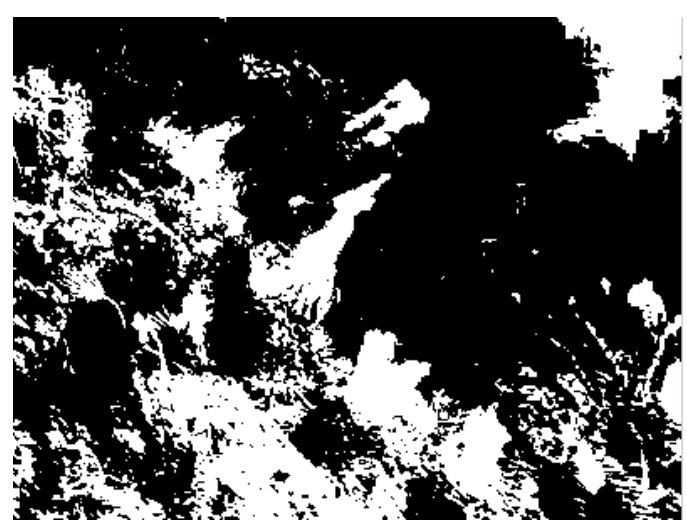

(b) 입력 영상에 대한 $F(x, y)$

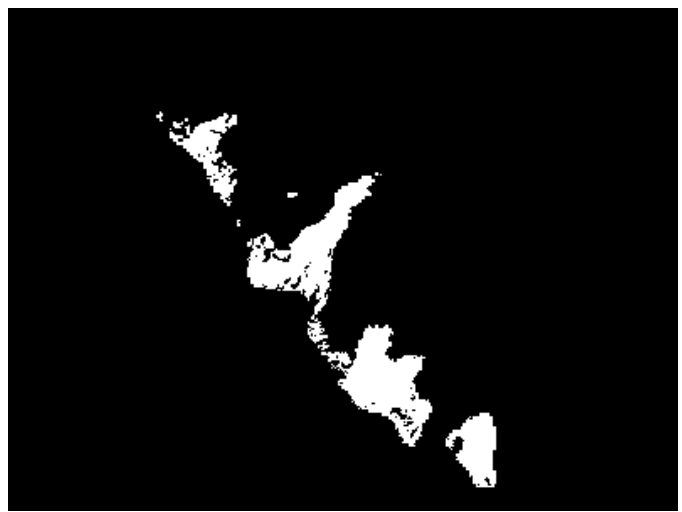

(d) 입력 영상에 대한 Flame $(x, y)$

그림 2. 화염 검출.

Fig. 2. Flame detection.

$$
\begin{aligned}
& Y_{\text {mean }}=\frac{1}{K} \sum_{i=1}^{K} \sum_{j=1}^{K} Y\left(x_{i}, y_{j}\right), \\
& C b_{\text {mean }}=\frac{1}{K} \sum_{i=1}^{K} \sum_{j=1}^{K} C b\left(x_{i}, y_{j}\right), \\
& C r_{\text {mean }}=\frac{1}{K} \sum_{i=1}^{K} \sum_{j=1}^{K} \operatorname{Cr}\left(x_{i}, y_{j}\right) .
\end{aligned}
$$

여기서 $K$ 는 단일 프레임에서 모든 픽셀의 개수이며 $\left(x_{i}, y_{j}\right)$ 는 프레임에서의 픽셀 위치를 나타낸다.

\section{2 조건 검사}

평균 성분 값과 각 픽셀의 성분 값을 이용하여 조건 검사
1. 화염에 해당하는 픽셀의 $\mathrm{R}, \mathrm{G}, \mathrm{B}$ 값의 크기가 $R \geq G \geq B$ 순서를 이룬다.

2. 단일 프레임 내에서 $\mathrm{R}$ 값들의 평균값 $R_{\text {mean }}$ 보다 화염 픽셀이 갖고 있는 $\mathrm{R}$ 값이 더 크다.

하지만 $R G B$ 모델은 조도의 영향을 크게 받기 때문에 일 조량에 따라 성능이 저하될 수 있다. 따라서 색차신호가 독립 적으로 존재하는 $Y O b C r$ 모델을 사용하는데 $Y$ 는 $C b$ 보다 크 며 $C$ 도 $C$ 보다 크다는 것을 이용할 수 있다[3]. 이러한 조 건식은 (3)과 같이 정의되고, 그림 2(a)의 입력 영상에 대해 
조건을 만족하는 출력 영상이 그림 2(b)에 나타나있다.

$$
F(x, y)=\left\{\begin{array}{c}
1, \text { if } Y(x, y)>C b(x, y), \\
\text { Cr }(x, y)>C b(x, y), \\
0, \text { otherwise. }
\end{array}\right.
$$

위의 조건을 만족하는 픽셀은 평균값과의 비교를 수행한 다. 불이 난 영역은 다른 영역보다 밝기 때문에 화염픽셀의 $Y$ 값은 평균 $Y$ 값보다 높다. 또한 주변 픽셀과의 관계를 고려한 검사는 식 (4)와 같이 정의된다. 화염은 $R G B$ 중 $\mathrm{R}$ 값이 상대 적으로 큰 값을 갖기 때문에 $C r$ 값은 평균 $C r$ 보다 크다. 또한 화염의 $C_{b}$ 값은 평균 $C_{b}$ 보다 작다는 것을 조건으로 이용한다. 식 (4)에 따른 결과 영상이 그림 2(c)에 나타난다.

$$
F^{\prime}(x, y)=\left\{\begin{aligned}
1, \text { if } & Y(x, y)>Y_{\text {mean }}, \\
& \quad b(x, y)<C_{\text {mean }}, \\
& C r(x, y)>C_{\text {mean }}, \\
& F(x, y)=1, \\
0, \text { otherwise. } &
\end{aligned}\right.
$$

이렇게 화염 후보로 판별되는 픽셀 가운데 $C b$ 와 $C$ 의 차 이가 일정 수준 이상되는 것을 화염으로 판단한다. 색차간 차 이는 화염 후보로 정해지는 픽셀의 범위를 조절하게 된다. 또 한 $R G B$ 의 상호관계를 고려하여 $R \geq G \geq B$ 의 조건을 추가 한다. $R(x, y), G(x, y) B(x, y)$ 는 각 픽셀의 $\mathrm{R}, \mathrm{G}, \mathrm{B}$ 값을 의 미한다. 최종적인 조건은 식 (5)와 같이 정의되고, 이 조건식 에 의해 화염으로 검출되는 영역을 그림 2(d)에서 보여주고 있다.

$$
\text { Flame }(x, y)=\left\{\begin{array}{l}
\text { if }|C b(x, y)-C(x, y)| \geq \tau, \\
1, \quad R(x, y) \geq G(x, y) \geq B(x, y), \\
\quad F^{\prime}(x, y)=1, \\
0, \text { otherwise }
\end{array}\right.
$$

위와 같은 화염 감지 알고리즘은 영상 평균을 이용하기 때 문에 조도의 변화에 강건하고 같은 이유로 야간에는 더욱 높 은 성능을 보인다.

\section{III. 연기 검출 알고리즘}

연기 검출은 배경과 현재 영상의 차를 이용한다. 기존에는 Wavelet 변환을 통해 연기의 주파수 특성을 분석하는 연구 $\lceil 11,12,13\rceil$ 가 활발히 진행되었지만, 산불 감시와 같이 원거 리에서 발생한 연기는 근거리 연기와는 주파수 특성이 다르기 때문에 적합하지 않다. 또 차영상을 이용하는 방법[14]은 배 경과 현재 영상의 차이를 구할 때 범위가 제한적이기 때문에
오검출의 가능성도 높다.

본 논문에서는 배경 영상을 구하고 현재 영상을 비교를 수 행한다. 이때 허용 범위를 갱신하는데 프레임간의 변화량을 가중치로 사용한다. 갱신된 허용 범위를 벗어나는 구간을 연 기후보로 지정한다. 또한 연기는 특정 색상을 지니지 않음을 이용하여 연기 후보 중에서 회색조를 띄는 픽셀을 최종적으로 연기로 판단한다.

\section{1 평균 성분 값 계산}

연기 검출은 인접한 프레임의 누적 평균과 현재 영상과의 차를 이용한다. 배경을 갱신하기 위해서는 먼저 각 픽셀들의 $R G B$ 평균값을 구하고, 식 (6)은 평균값을 구하는 공식을 나 타낸다. $N$ 은 참조할 인접 프레임의 개수를 말하며 $I_{i}(x, y)$ 는 $i$ 번째 입력 영상의 $(x, y)$ 위치의 픽셀값을 나타낸다.

$$
\operatorname{Mean}(x, y)=\frac{1}{N} \sum_{i=1}^{N} I_{i}(x, y) \text {. }
$$

\section{2 후보 범위 설정 및 최종 판단}

후보 범위를 설정하기 위해서는 누적된 영상들의 평균 픽 셀값과 현재 영상의 픽셀값 사이의 차이를 구하고, 그 차이에 제곱을 취해줌으로써 가중치를 부여한다. 이렇게 얻어진 가중 치에 $\operatorname{thr} 1$ 만큼의 상수를 곱해서 범위를 확대하고, 비율을 맞 추기 위해 제곱근의 형태를 취한다. 최종적으로 $K$ 프레임의 평균값을 구한다. 이렇게 얻어낸 $B g(x, y)$ 는 평균 영상과 현 재 영상을 비교할 때 어느 정도의 차이를 배경으로 인식할 것 인지 범위를 결정하게 된다. 식 (7)은 이러한 과정을 나타내 는 공식이다.

$$
B g(x, y)=\frac{1}{K} \sum_{i=1}^{K} \sqrt{\mid \text { Mean }(x, y)-\left.I_{i}(x, y)\right|^{2} \times t h r 1} .
$$

식 (7)을 통해 얻어진 가중치를 이용하여 배경이 가질 수 있는 범위를 갱신한다. 평균 픽셀값에서 가중치와 경계값을 빼준 값을 $\operatorname{Low}(x, y)$, 평균 픽셀값과 가중치와 경계값을 더해 준 값을 $\operatorname{Upper}(x, y)$ 라고 정의하며 이를 나타낸 공식은 식 (8)와 같다. 경계값인 $t h r 2$ 는 실험에 통해 결정한다.

$$
\begin{aligned}
& \operatorname{Low}(x, y)=\operatorname{Mean}(x, y)-\operatorname{Bg}(x, y)-t h r 2, \\
& \operatorname{Upper}(x, y)=\operatorname{Mean}(x, y)+B g(x, y)+t h r 2 .
\end{aligned}
$$

식 (9)는 이렇게 영상 범위가 구해졌을 때 현재 입력영상 
$I_{n}(x, y)$ 의 픽셀 값이 범위 내에 포함되는지 검사하는 수식이 다. 범위 내에 있는 픽셀은 1 , 범위 밖의 값을 갖는 픽셀은 0 으로 이진화한다. 여기서 1 은 배경 영역, 0 은 연기 후보 영 역이다.

$$
\operatorname{Mask}(x, y)=\left\{\begin{array}{l}
1, \text { if } \operatorname{Low}(x, y) \leq I_{n}(x, y)<\operatorname{Upper}(x, y), \\
0, \text { otherwise }
\end{array}\right.
$$

최종적으로 연기를 판단할 때는 $\operatorname{Mask}(x, y)$ 가 0 인 픽셀, 즉 연기 후보로 판단된 픽셀이 회색조를 띄고 있는지 검사한 다. 연기는 특정 색상을 갖지 않으므로 $R G B$ 간의 색차가 적 은 특징을 이용하는 것이다. 식 (10)은 연기를 최종적으로 판 단하는 공식을 나타낸다.

$$
\operatorname{Smoke}(x, y)=\left\{\begin{array}{c}
1, \text { if } \alpha-\beta<I_{R}(x, y)<\alpha+\beta, \\
\alpha-\beta<I_{G}(x, y)<\alpha+\beta, \\
\alpha-\beta<I_{B}(x, y)<\alpha+\beta, \\
\operatorname{Mask}(x, y)=0, \\
0, \text { otherwise. }
\end{array}\right.
$$

여기서 $I_{R}(x, y), I_{G}(x, y), I_{B}(x, y)$ 는 입력영상 픽셀의 $\mathrm{R}$, $\mathrm{G}, \mathrm{B}$ 값을 각각 나타낸다. 또한 는 해당 픽셀의 $\mathrm{R}, \mathrm{G}, \mathrm{B}$ 평균 값이며 $\beta$ 는 경계값이다. 실제 실험에서는 배경이 연기영역보 다 누적되는 속도를 빠르게 하여 새롭게 발견되는 영역에 대한 민감도를 높였다. 이와 같은 연기 검출은 일련의 과정을 반복 적으로 수행하면서 배경을 누적 갱신하고 현재 영상과 비교함 으로써 새롭게 감지되는 움직임을 효과적으로 판단할 수 있다.

\section{IV. 실험 결과}

본 절에서는 실제 산불 영상을 통해 제안하는 알고리즘을 테스트하고 성능을 판단한다. 영상은 $320 \times 240$ 의 크기이고 초당 15프레임이다. 실험은 Pentium Core2Duo $2.13 \mathrm{GHz}, 2 \mathrm{~GB}$ 의 메모리를 가진 시스템에서 이루어졌다. 화염 감지 알고리즘을 비교하기 위한 대상으로는 $R G B$ 컬러 공간을 이용한 Chen[2]의 알고리즘을 사용하였다. 또한 실 험 영상의 각 프레임의 화염 몇 연기 발생 유무를 육안으로 관찰하여 해당 알고리즘의 산불 검출의 정확도를 기록하였으 며 화염과 연기 감지 테스트는 서로 독립적으로 이루어졌다.

표 1은 실험에 사용한 동영상 정보를 나타낸다. Scene 1과 Scene 2 동영상은 화염이 발생하는 영상이고, Scene 2 동영 상은 연기가 발생하는 영상이다. Scene 4 동영상은 연기와 화 염이 모두 발생하지 않는 일반 영상이다. 표 2 는 $R G B$ 색상
공간을 이용한 기존의 알고리즘의 검출 성능을 나타낸다.

표 2 에서 나타나듯이 기존의 알고리즘은 화염을 검출하는 성능은 뛰어나지만, 반대로 오검출 비율도 높다. 특히 일반 영상인 scene 4 의 경우 화염이 발생하지 않은 전체 226장의 프레임 중에서 222 장에서 화염을 오검출하였다. 위와 같은 결과는 일조량에 따른 조도의 변화에 민감하게 반응하는 기존 의 알고리즘의 문제점을 단적으로 보여준다. 제안하는 알고리 즘의 실험은 주간과 야간을 각각 테스트하였고, 실험에 사용 되는 민감도 경계값 $(\tau)$ 는 40 으로 설정하였다.

\section{표 1. 실험 동영상 목록.}

Table 1. List of the experimental image sequences.

\begin{tabular}{|c|c|c|c|}
\hline 목록 & 전체 프레임 & $\begin{array}{c}\text { 화염 } \\
\text { 프레임 }\end{array}$ & $\begin{array}{c}\text { 연기 } \\
\text { 프레임 }\end{array}$ \\
\hline $\begin{array}{c}\text { Scene 1 } \\
\text { 화염 영상 }\end{array}$ & 116 & 116 & $\cdot$ \\
\hline $\begin{array}{l}\text { Scene 2 } \\
\text { 화염 영상 }\end{array}$ & 306 & 274 & $\cdot$ \\
\hline $\begin{array}{l}\text { Scene 3 } \\
\text { 연기 영상 }\end{array}$ & 453 & 0 & 389 \\
\hline $\begin{array}{l}\text { Scene 4 } \\
\text { 일반 영상 }\end{array}$ & 226 & 0 & 0 \\
\hline
\end{tabular}

표 2. 기존 알고리즘의 화염 검출 성능.

Table 2. Flame detection performance of conventional algorithm.

\begin{tabular}{|c|c|c|c|}
\hline $\begin{array}{c}\text { 실험 } \\
\text { 영상 }\end{array}$ & 화염 프레임 & 검출 프레임 & 신뢰도 \\
\hline Scene 1 & 116 & 116 & $100 \%$ \\
\hline Scene 2 & 274 & 306 & $88.3 \%$ \\
\hline Scene 4 & 0 & 222 & $1.7 \%$ \\
\hline
\end{tabular}

그림 3의 (a)와 (b)는 각각 입력 영상과 화염 검출 영상의 예이다. 그림 3 의 $(\mathrm{b})$ 에서 사각형 테두리 안에 있는 진한 붉 은색 영역이 화염이라고 판단되는 부분이다. 그림 3 의 (c)와 (d)는 야간 산불영상에 대한 실험 영상이고 표 3 은 위의 실험 들의 결과를 나타낸다. 산불이 발생한 경우에는 경계값 $(\tau)$ 이 성능에 큰 영향을 주지 않음을 확인할 수 있다. 


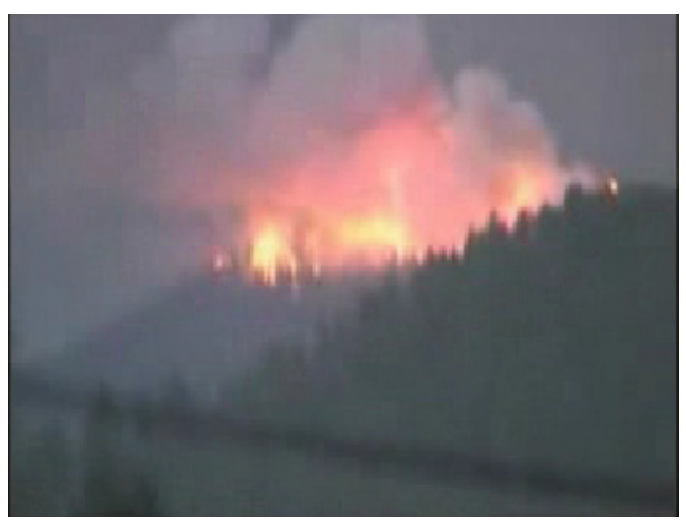

(a) 주간 영상 입력.

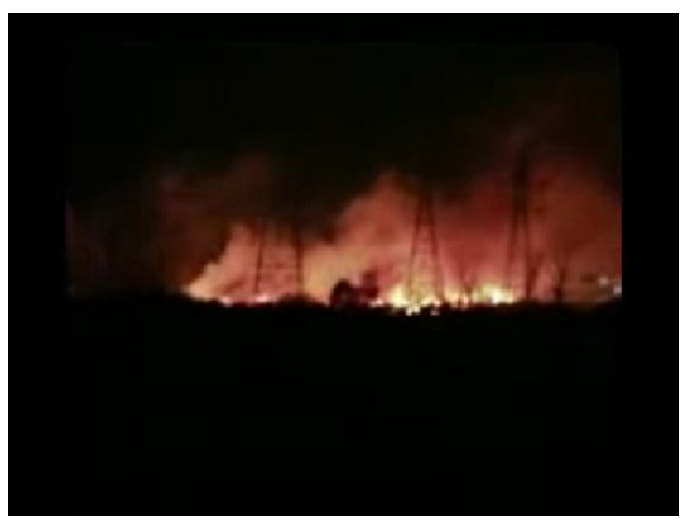

(c) 야간 영상 입력.

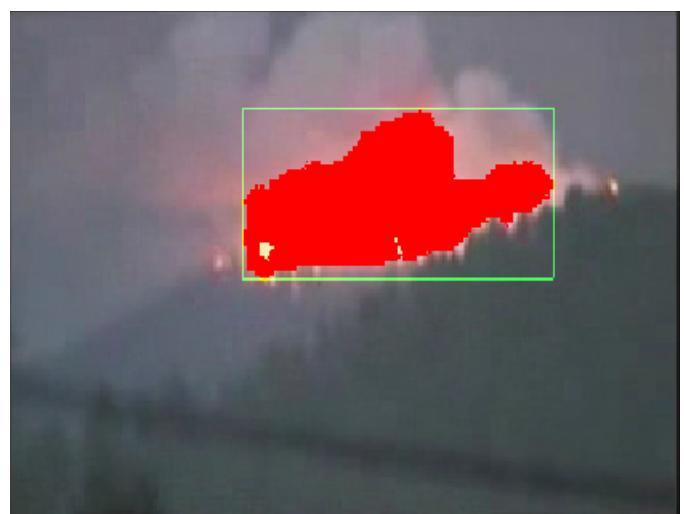

(b) 주간 영상의 화염 검출.

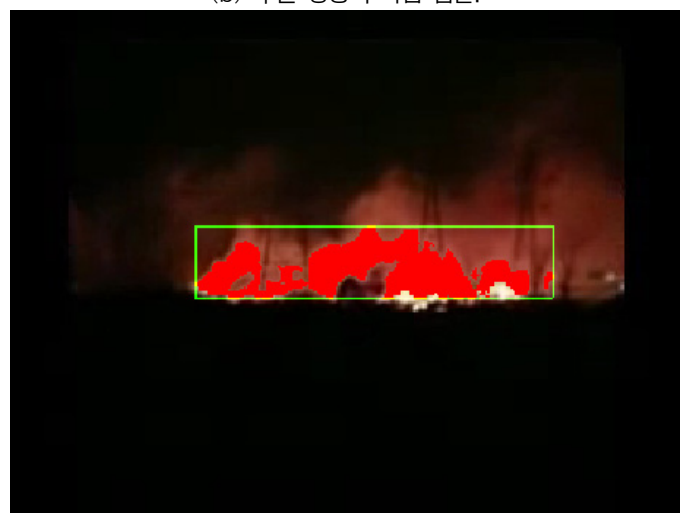

(d) 아간 영상의 화염 검출.

그림 3. 주간 및 야간 영상의 화염 검출.

Fig. 3. Flame detection in the day and nighttime.

표 3. 제안하는 기법의 화염 검출 성능.

Table 3. Flame detection performance of the proposed algorithm.

\begin{tabular}{|c|c|c|c|c|}
\hline 구분 & $\begin{array}{l}\text { 실험 } \\
\text { 영상 }\end{array}$ & $\begin{array}{c}\text { 화염 } \\
\text { 프레임 }\end{array}$ & $\begin{array}{c}\text { 검출 } \\
\text { 프레임 }\end{array}$ & 신뢰도 \\
\hline \multirow{2}{*}{ 주간 } & \multirow{2}{*}{ Scene1 } & 116 & $116(\tau=40)$ & $100 \%$ \\
\hline & & 116 & $116(\tau=60)$ & $100 \%$ \\
\hline \multirow{2}{*}{ 야간 } & \multirow{2}{*}{ Scene2 } & 274 & $274(\tau=40)$ & $100 \%$ \\
\hline & & 274 & $271(\tau=60)$ & $98.9 \%$ \\
\hline
\end{tabular}

표 4는 산불이 발생하지 않은 영상을 사용한 실험 결과이 다. 산불이 발생하지 않은 경우에는 산불이 발생한 경우와는 달리, 알고리즘에 사용되는 경계값 $(\tau)$ 의 수치에 따라 성능이 달라지는 것을 확인할 수 있다. 이는 상황에 맞는 경계값 설 정이 필요함을 의미한다.
표 4. 경계값에 따른 화염 검출 성능.

Table 4. Flame detection performance according to threshold values.

\begin{tabular}{|c|c|c|c|}
\hline 실험 영상 & 화염 프레임 & 검출 프레임 & 신뢰도 \\
\hline Scene 4 & 0 & $0(\tau=40)$ & $100 \%$ \\
\hline Scene 4 & 0 & $3(\tau=35)$ & $98.2 \%$ \\
\hline Scene 4 & 0 & $55(\tau=30)$ & $75.6 \%$ \\
\hline
\end{tabular}

연기 검출에 대한 실험 결과가 그림 4에 나타나있다. 그림 4 의 (a)는 배경 영상, (b), (c)는 각각 입력 영상과 연기 검 출의 이진 영상이다. 그림 4 의 (d)는 연기 검출 결과를 나타 내는데 초록색으로 나타나는 영역이 연기로 판단된 영역이다. 표 5 는 그림 4 와 같은 영상의 실험 결과이다. 표에서 보는 바 와 같이 제안하는 알고리즘은 389 개의 연기 프레임 중에서 356 개의 프레임을 검출하는 높은 신뢰도를 가지고 있다. 


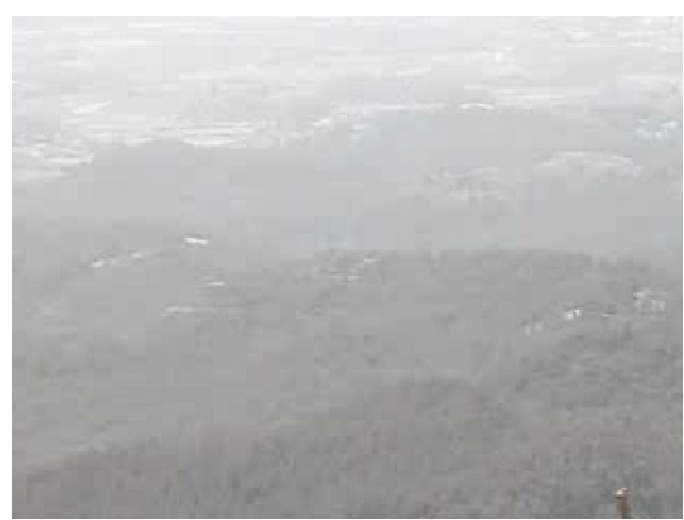

(a) 배경 영상.

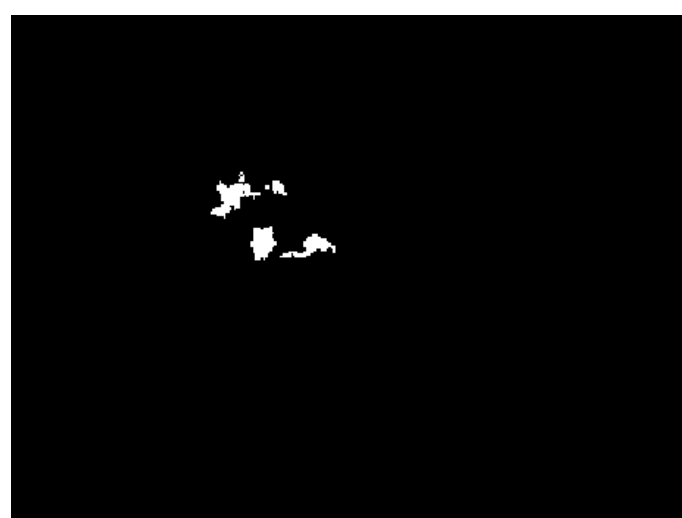

(c) 연기 검출의 이진 영상.

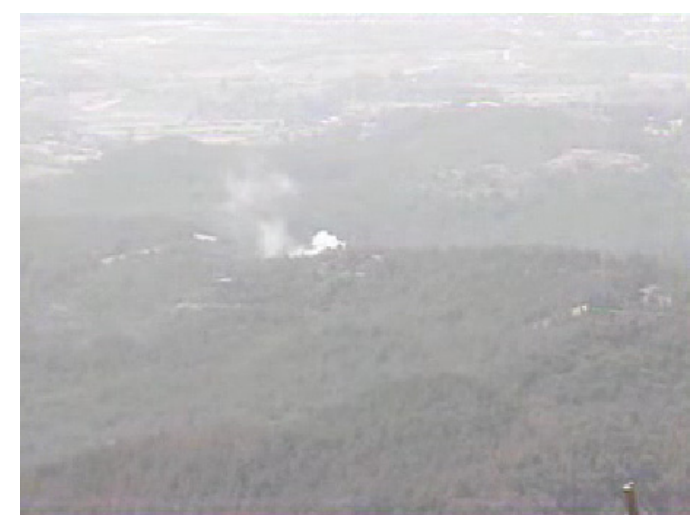

(b) 입력 영상.

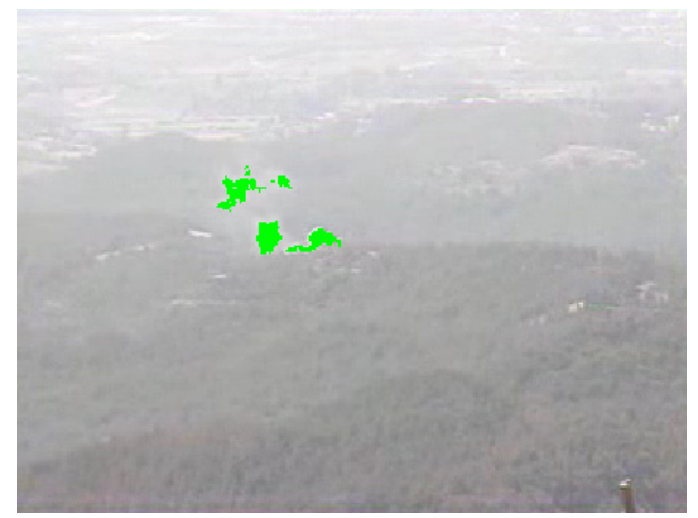

(d) 연기 검출 영상.

그림 4. 연기 검출.

Fig. 4. Smoke detection.

표 5. 실험 영상에 대한 연기 검출 성능.

Table 5. Smoke detection performance of the proposed algorithm.

\begin{tabular}{|c|c|c|c|}
\hline 실험 영상 & 연기 프레임 & 검출 프레임 & 신뢰도 \\
\hline Scene 3 & 389 & 356 & $91.5 \%$ \\
\hline
\end{tabular}

\section{V. 결 론}

본 논문에서는 $Y C b C r$ 컬러 모델에서의 조건 검사와 인 접한 프레임의 평균 영상을 이용한 배경의 범위를 정하는 방 법으로 화염과 연기를 효과적으로 검출하였다. 특히 화염 감 지 알고리즘은 기존의 알고리즘보다 일조량에 따른 조도의 변
화에 강건하고, 또한 야간에도 화염을 효과적으로 검출함을 의미하며 실험을 통해 성능을 확인하였다. 연기 검출 또한 단 위 시간 동안의 변화량을 고려하기 때문에 새롭게 변화하는 구간을 효과적으로 검출한다. 위와 같은 화염, 연기 검출 알 고리즘을 통해 산불의 조기 탐지가 가능하다.

과거 화염을 감지하는 기법에는 $R G B$ 모델을 사용하여 광 원과 조도에 따라 성능이 크게 바뀌었다. 또 연기를 감지할 때는 근거리에서 탐지하였다. 하지만 본 논문에서 제안된 알 고리즘은 광원과 조명에 강건한 화염감지가 가능하고, 산불과 같이 원거리에서 발생한 연기를 감지하는데 더 우수한 성능을 보인다. 향후에는 화염과 연기의 발생 특성을 상호 고려한 검 출 알고리즘을 추후 연구를 통해 제시하고자 한다. 


\section{참고문헌}

〔1〕 이두희, 유재욱, 이강희, 김 윤, "실시간 산불 감지를 위한 화염 및 연기 검출 기법, 2010년 한국컴퓨터정보학회 동 계학술대회 논문집 제 18 권, 제 1호. 145-148쪽, 2010 년 1월.

〔2] T. Chen, P. Wu, Y. Chiou, "An early fire-detection method based on image processing," In Proceedings of IEEE International on Image Processing, pp. 1707 - 1710, Oct. 2004.

[3] Thou-Ho. Chen, Cheng-Liang. Kao and Sju-Mo. Chang, "An intelligent real-time fire-detection method based on video processing," In Security Technology, 2003. Proceedings. IEEE 37th Annual 2003 International Carnahan Conference, pp. 104-111, Oct. 2003.

[4] Jessica Ebert, Jennie Shipley, "Computer vision based method for fire detection in color videos," In International Journal of Imaging 2009, Spring, Volume 2, 2009.

[5] Cappellini. V, Mattii. L. and Mecocci. A, "An intelligent system for automatic fire detection in forests," In Image Processing and its Applications Third International Conference 1989, pp. 563-570, July 1989.

[6] Turgay Celik, Huseyin Ozkaramanh and Hasan Demirel, "Fire and smoke detection without sensors: image processing-based approach," In Proc. 15th European Signal Processing Conf. pp. 1794-8, Sep. 2007.

(7) Turgay Celik, Hasan Demirel, "Fire detection in video sequences using a generic color model," Fire Safety Journal 44, pp. 147-158, Aug. 2009.

[8] W. Phillips, M. Shah, N. da Vitoria Lobo, "Flame recognition in video," In Pattern recognition letters, Jan. 2002.

[9] Ko B C, Cheong K H and Nam J Y, "Fire detection based on vision sensor and support vector machines," In Fire Safety Journal, Volume 44, Issue 3, pp. 322-329, Apr. 2009.

〔10] G. Marbach, M. Loepfe and T. Brupbacher, "An image processing technique for fire detection in video images," Fire Safety Journal, Volume 41, Issue 4, pp. 285-289, June 2006.

[11] B. Ugur Toreyin, Yigithan Dedeoglu and A. Enis Cetin, "Wavelet based realtime smoke detection in video," In 13th Eur. Signal Process. Conf. EUSIPCO, Sept. 2005.

〔12〕 B. Ugur Toreyin, Yigithan Dedeoglu, Ugur Gudukbay and A. Enis Cetin, "Computer vision based method for real-time fire and flame detection," In Pattern Recognition Lett. 27 (2006), pp. 49 - 58, Jan. 2006.

〔13] B. Ugur Toreyin, Yigithan Dedeoglu, and A. Enis Cetin, "CONTOUR BASED SMOKE DETECTION IN VIDEO USING WAVELETS," European Signal Processing Conference, EUSIPCO-06, Sept. 2006.

〔14] Z. Xiong, R. Caballero, H. Wang, A.M. Finn, M. A. Lelic, P.-Y. Peng, "Video-based smoke detection: possibilities, techniques, and challenges," In SUPDET, Mar. 2007.

〔15〕 이병무, 한동일, "터널 화재의 실시간 조기 탐지를 위한 화염 및 연기 검출 기법," 2008년 7월 전자공학회 논 문지 제 45 권 SP 편 제 4 호. 59-70쪽, 2008년 7월.

[16] Wieser D, Brupbacher T, "Smoke detection in tunnels using video images," In 12th international conference on automatic fire detection, Gaithersburg, USA, Mar. 2001.

〔17〕 Luis Merino, Fernando Caballero, J. R. Martinez-de Dios, Joaquin Ferruz and Anibal Ollero, "A cooperative perception system for multiple UAVs: Application to automatic detection of forest fires," In Journal of Field Robotics, Vol. 23, Iss 3-4, pp. 165-184, Feb. 2006.

[18] C. A. Poynton, "A Technical Introduction to Digital Video," John Wiley \& Sons, 1996. 


\section{저 자 소 개}

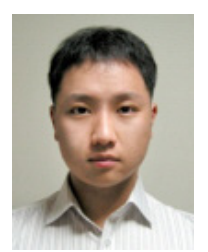

이 두 희

2010: 강원대학교 공학사.

2010 - 현재 : 강원대학교 컴퓨터정 보통신공학과 석사과정

관심분야 : 영상 처리, 컴퓨터 비전

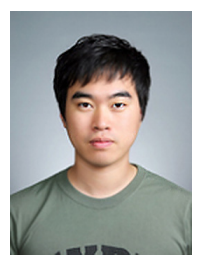

\section{유 재 욱}

2009: 강원대학교 공학사.

2009 - 현재 : 강원대학교 컴퓨터정 보통신공학과 석사과정

관심분야 : 영상 처리, 코덱

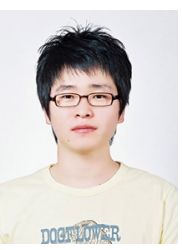

이 강 희

2009: 강원대학교 공학사.

2009 - 현재 : 강원대학교 컴퓨터정 보통신공학과 석사과정

관심분야 : 영상 처리, 컴퓨터 비전

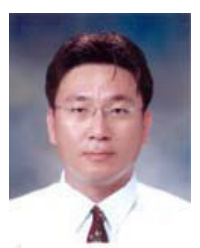

김 윤

1993: 고려대학교 공학사.

1995: 고려대학교 공학석사.

2003: 고려대학교 공학박사

2004 - 현재: 강원대학교 컴퓨터정보

통신공학과 부교수

관심분야 : 영상 신호 처리, 멀티미디

어 통신 및 처리 